\title{
Sobre o diagnostico das sequelas mentaes da encephalite lethargica nas creanças
}

Entre as sequelas da encephalite lethargica, as desordens menta se destacam pela sura frequencia, o quadro clinico muito particular que ellias offerecem.

$\mathrm{Na}$ creança sobretudo, as formas mentaes não são raras, devendo ser cuidiadosamente restudladas, porquanto ha casos frustos, em que as somaticas são pouco promunciadals, occuplando as perturbações psychicas, o primeiro plano.

Vamos relatar, duras observações clinicas colhidas no Hbspital do Juquery, procurando stalientar, os principaes elementos das perturbações psychicas.

\section{OBSERVAÇÁO N. I}

Nome - Orlando Gattai.

Nacionalidade - Brasileira.

Estado civil - Solteiro.

Edade -14 annos.

Instrucção - Regular.

Procedencia - São Paulo.

Data de entrada -26 de Jameiro de 1925.

Antecedentes hereditarios - Segundio suas proprias informações, os paies possuem saude perfeita. Diz ter ısete irmãos e ajunta que todos são sadios.

Não ha na familia antecedente de molestias mentaes.

Foi constatada a veracidade de suas informações.

Antecedente pessoaes - Pelas informações adquiridas e pelas tomadas ao proprio doente, quanto a seus antecedentes pessoaes, declara ter sido 
forte, até a época do inicio da molestia que o attingiu, e da qual elle propirio apresenta a sequella.

Por affirmações de pessoas da familia, nós soubemos, que elle foi sempre um menino de genio impu'sivo/ e irrequieto.

Faz sete mezes, elle foi attingido pela encephalite lethargica, e conforme os dados do illustre clinico que o medicou, dr. Ribeiro de Almeida, o nosso doente apresentou os symptomas banaes de encephalite lehargica, taes como: scmonlencia accentuada, diplopia, etc.

Passou por um estado de lethargia prolongado, que durou vinte e um dias, durante o qual, era despertado por pessoas da familia, para poder alimentar-se, o que fazia com alguma difficuldade.

Passada essa phase aguda da molestia, o que o nosso doente poude levantar-se do leito, manifestaram-se, dahi algum tempo, as perturbações mentaes, que trouxeram a familia, a internal-o neste hospital, e sobre as quaes referir-nos-hemos mais adiante.

Exame geral do doente - $\mathrm{O}$ irdividuo apresenta-se bem disposto, paniculo adiposo regularmente desenvolvido. Fossas supra-claviculares pouco accenturadas entretanto a direito é maịs que o lado esquerdo. A sua sabeça soffreu uma ligeira rotação para o lado direito, com uma evidente contractura do trapezia, e sterno-cleidomastoideu. $O$ thorax é assymetrico, tanto na sua parte anterior, quanto na posterior. $\mathrm{Na}$ anterior, $\mathrm{o}_{\text {; }}$ sterno apresenta-se desviado para a esquerda, com uma concavidade voltada para o lado esquerdo.

$\mathrm{Na}$ parte posterior evidencia-se, scoliose, com uma curvatura superior maior, com a concavidade voltada tambem para a esquerda.

O hombro direito, acha-se mais elevado que o esquerdo, tendo o relevo muscular que o caracterisa. Nota-se ahi a contractura do supra-espino.

$\mathrm{Na}$ face anterior do pé esquerdo, está uma empinge.

O menino é forte, bem desenvolvido.

$\mathrm{Na}$ sua fronte, assignalam-se rugas transversaes, consequencia da elevação constante dos supercilios. Esse movimento constante, dos musoulos frontaes, é devido, a uma ophtalmoplegia externa, que elle procura attenuar, com a inclinação da cabeça para traz.

Quando falla, faz certo esforço, para pronunciar as palavras.

Apresenta contracções involuntarias dos musculos do pescoço, porem não coml rythmo e frequencia, que o fazem inclinar a cabeça para traz e para a direita (tiques). 
A sua vóz é anasalada, não havendo itodavia, paralysia das cordas voca'es.

O naso-pharinge apresenta porem vegetações adeno:des.

No pescoço elle apresenta dor á pressão, e principalmente ao nivel da insersão do trapezio direito.

A cabeça é irregularmente conformada, dentes cariados, orelhas pequenas e achatadas. Uvula e abobada palatina, perfeitamente normaes.

Prenis bastante desenvolvido para a idade, denunciando uma puberdade precoce.

Apparelho respiratorio - Pela inspecção, nota-se que a expansão pulmonar do lado direito, encontra-se diminuida, por causa mesmo das contracturas musculares permanentes, evidenciadas desse lado.

O fremito thoraco-vocal, acha-se ahi, um tanto augmentadio.

Vemos, porem, que os signaes semeiologicos, desse lado do thoraxrencontrami-se um tanto modificados, tão sómente, por causa das contracturas musculares evidenciadas, e que não ha propriamente lesões organicas, na principal parte do apparelho respiratorio.

Apparelho cardio-vascular - A não ser um pequeno reforço da segunda bulha card:aca, não encontaamos nada de anormal nesse apparelho.

Exame neurologico - A estatistica é relativamente perfeita.

Marchia normal. O exame dos reflexos revelou-nos o seguinte:

tendinosos no membro superior bem diminuidos. Tricipital quasi que completamente abolido. Bicipital, e longo-supinador, tambem muito diminuidos, e is to tanto para o membro esquendo como para o direito.

Os dos membros inferiores, encontram-se tambem modificados, estando diminuido para ambos os lados.

Sensibilidade, profunda e superficial conservadas.

Ao exame visual, revela-se um ptosis attenuadia bilateral, com um ligeiro estrabismo divergente, e abalos nystagformes.

Reflexo pupilar modificados, reagind oambas as pupilas com certa preguiça, ao golpe de luz. Ha certa paresia nos rectos internos.

Babinski ausente bilateral. Romberg negativo.

Exame psychico - Tem instrucção primaria, quasi completa; sabe ler e escrever regularmente. Effectua as operações arithmeticas com relativa fac:lidade. 
A attenção ainda é booa, e a comprehensão perfeita.

Possue a associação de normal. Limpo e asseiado comle e veste-se com ordem

Satisfaz as necessidades physiologicas como os demais, procurando os lugares apropriados. Ajuda os empregados nos serviços que thes são indicados, e term ás vezes carinhos, para com seus companheiros, repartindo os alimentos com elles.

Ponem ttudo isso não é normal, digo regular, pois longe da nossa presença, mostrava-se raivoso, colerico, impulsivo, aggredindio os companheiros, e como é violento, é tambem por elles temlido.

Algumas vezes abraça-nos com choros immotivados, dizendo que the querem cortar o pescoço. Elle tanito chora ou ri por motivos futeis, e a passagem do facies de choro para o de riso, é feita sem aquella gradativa transformação mimica. A respeito do seu somno, o enfermeiro mos conta, e elle mesmo nos diz, que algumas vezes dorme durante todo o dia e tambem toda a noite.

Em virtude do seu caracter assim violento, para boa ordem do serviço hospitalar, teve que ser levado para a enfermaria de adultos. De facto, foi internado na $4 i^{\mathrm{a}}$ enfermaria de homens.

Ahi então, tem se tornadio melhor, porem sempre manifestando o seu caracter irrequieto. Dános informações de sua familia, e diz que quer escrever ao pae, sem todavia parecer entrar nisso a menor satisfacção de affectividade. O seu facies apezar de não sser atomo, apresenta uma relativa estabilidade, sendo tanto o seu choro, quanto o seu riso, pouco expressivos. Não se trata aqui, propriamlente da rigidez parkinsoniana, mas seria, se não fosxe mola audacia dizel-o, uma mascarra, que całracterisania um estado sub-parkinsoniano.

'Não ha, manifestações de ideas absurdas, pelo test de RavaultAllornes.

$\mathrm{O}$ acto de querer, encontra-se nelle, um tanto modificado, porque ao obedecer em dados momentos ás mossas ordens, fal-o ccmo se fosse um automato. A respeito do seu instincto sexual, diz-nos o enfermeiro, que elle se masturba, com manifesto exhibicionismo, havendo em certa occasião. tentado levar um seu companheiro, a um acto de pederestia passiva.

Como se deprehrende, do que acabamos de ler nesta observação, no caso presente as sequellas sturdicas aqui são, não muito pronunciadas, não havendo, nem o apparecimento de um syndromo excito-motor claramente 
definido, com os seus movimentos choreicos, com as suas bradycinesias, as suas myoclonias, etc., retialva da contractura involuntaria dos musculos do pescoço, que por ser um choque muscular, não é todavia um choje rapido, explosivo, rythmado, que foi como assignalou a contracção myoclonica.

Não ha, tão pouco, um syndromo parkinsoniano.

Não dizemos que ha, manifestações tardias de ordem geral, porquanto não podemos levar em conta, aquelle pequeno impecilho respiratorio, occasionado pelas cantracturas musculares permanentes.

Nós estamos sim, em presença, de manifestações tardia de ordem neuro-muscular, e principalmente de perturbações de ordem psychica.

As de ordem neuro-muscular, nós já vimos com as contracturas, e os reflexos alterados, indicando que as vias pyramidal, e extra-pyramidal, não se encontram integras.

Vamos examinar as perturbações de ordem psychica.

Como vimos, o nosso doente tinha no seu estado pre-morbidio, um caracter impulsivo, e violento. Isto tem certa importancia, porque certos autores tem assignalado, que o doente no estado post-morbido, apresentando perturbações para o lado physico, ạs manifestações affectivas, são a exaggeração do caracter habitual, e não provocadas exclusivamente pela molestia.

Trata-se como diz Kleist, de reacções individuaes, em relação á situação creadia pelo estado morbido. Assim nesse sentido, elle apresenta doentes, que anteriormente possuiam um caracter placido, e no periodo post-morbido, esse traço psychïco, exagerou-se no sentido de uma inercia mental quasi que absoluta.

No nossa caso, vimos que o doente, se manifesta violento e impulsivo, tendo mesmo, tentado fugir algumas vezes do hospital.

Conseguiuo numá dessas vezes, sendo porem preso em Pirituba.

O aspecto puramente intellectual do psychismo, mostra-se inteiramente normal.

De facto elle apresenta a intelligencia prompta, raciocinio lucidio, e comprehensão facil. Aliás, em casos semelhantes, nós podemos encontrar, como fizeram ver alguns autores, as faculdades puramente intellectuaes, não attingidas (SANCHIS-BANUIS, PELLANCANI, etc).

Sanchis-Banus accentua que ha um typo de sequellas mentaes, que se apresenta com mais frequencia nas creanças, independentes da forma 
clinica da encephalite, e da constituição individual, e que não se acompanhando, die signaes neurologicos, apresentami porem esta triade symptomatica: inemnia, alterações de caracter, e alterações de habitos.

Quianto ás alterações de affectividade, vimos que ellas se evidenciam no nosso doente, pelo chorar immctivado, bem como não manifestar nenhuma reacção emocional ao referir-se ás pessoas da familia.

A volição, enccntra-se nelle como assignalamos, um tnato atting:da.

A ccentuamos o cedo iniciar, do instincto sexual, o que é logico, pois a vista da precice puberdade, o psychismo sexual, força tem que estar a par com elle. Já foi assignalado, tambem por alguns autores, estes phemomenos sexuaes morbidos, como sendo um dos mais constantes symptomas sequellares.

\section{OBSERVAÇĀO N. II}

Nome - Salim Sahadeh.

Naciomalidade - Syria.

Estado Civil - Solteiro.

Instrucção - Boa.

Edade - 15 annos.

Procedencia - ? ?

Antecedentes hereditarios $\rightarrow$ Não ha informações a respeito die seus artecedentes hereditarios.

Antecedentes pessoaes - Declara o. nosso doente, que até a época da molestia que o prostrou, foi sempre sadio, não accusando mesmo as molestias peculiares á infancia. Foi sempre um menino intelligente, de genio calmlo, obediente, afinal com um conjuncto de qualidades, que faziam com que fosse estimado por todos. Seguramente ha tres annos, elle foi attingido pela eceph. letharg. que se manifestou symytomaticamente, por delirios e estupor, estabelecendo-se uma certa espec:e de lucta, na predominancia, pois alternavam-se.

Por fim como geralmente se dá, e Pienkowski o diz, houve a supremacia do estado estuporadio, com uma lethargia que durou alguns dias.

Medicado convenientemente, desappareceram esses symptomlas, que caracterisavam a phase aguda da molestia, para tempos depo.s, entrar a enceph. na sua phase sequellar, ou chronica como quer Pienkowski a a grande maioria dos autores. 
Caracterisou-se esse periodo, pela mudança do seu psychico, e principalmente das suas qualidades moraes, que obrigaram a familia a internal-o neste Hospital.

Exame somatico - A respeito dos seus apparelhos respiratorio e circulator:o, nada temos a dizer, pois elles se mostrami apparentemente perfeitos.

Todavia pelo aspecto geral, o doente se apresenta emmagrecido, alimentando-se pouco e quasi que exclusivamente de liquidos, pois encontra serias difficuldades em deglutir solidos.

Evidencia-se nelle, uma hemiplegia parkinsoniana, do lado esquerdo, com rigidez do pescoço, tremores no membro sup. esquerdo; e retracção dos musculos das pantorrilhas do membro inferior do mesmo lado.

Em virtude dessa retracção, elle encontra serias difficuldades, em locomover-se, po:s que o pé foi repuxado em virtude mesmo das retracções muscularles, para dentro para cima (pied-bot).

Ha nelle, o phenomeno da kinesia paradoxal.

Para locomover-se, fal-o muito melhor rapidamente, do que devagar.

Exame neurologico - Sensibilidades normaes.

Reflexos: os dos miembros superiores pouco alterados: Os dos membros inferiores. Rotulianos e achilianios pouco alterados. Babinski a esquerda.

A direita flexão esboçada, Anisocőria, pupila esquerda maior que a direita. Reflexos a accommodação e a luz presentes.

Sudorese abundante, maior do lado esquerdo.

Exame psychico - Grau de cultura para a sua idade, um tanto desenvolvida. Conhece bem o inglez, tem conhecimento de francez e allemão. Sabe geographia, historia, pờrem aqui os seus conhecimentos são mais restrictos. Faz pequenos calculos arithmeticos.

Comprehensão perfeito, memoria idem.

A attenção está um tanto modificada. Ao relatar um facto qualquer fal-o muito bem no principio, mas dahi a pouco, como que a attenção foge, não no sentido de fixar-se em outra cousa, mas como que cansada, exgota-se. Vê-se o esforço que elle faz para retomal-a, o que consegue somente por algu'ns instantes, para depois apresentar o mesmo phenomeno.

Resulta disso que a sua falla já de si um tanto monotona, e arrastada, torna-se nessas occasiões, vagarosa, chegando a momentos em que elle não 
articula uma palavra. Poremi quando elle consegue retomar a attenção, diz uma porção de palavras depressa.

'Possue perfeita noção de tempo, lugar, e meio.

Actualmente apresenta um estado de hypomania ligeira, evidenciado por risos frequentes e traquinices.

Tem bruscas mudanças de humor, com risos e choros immotivadso.

Insomnia agitada, pois levanta'se á noite e importuna os companheiros. Ultimamente como o seu estado de fraqueza não o permlitte, põese a gritar em altas vozes. $E^{\prime}$ onamista confesso, e conta rindo-se que não póde deixar masturbar-se. Algumas vezes manifesta-se violento, impulsivo, e tem frequentemente ataques epileptiformes. Passando-se á analyse, temos que neste caso o mosso doente apresenta, um syndromo excito-motor, assiciado a um syndromo parksoniano e, a outras manifestações tardias, que são, as de ordem neurologica, as de ordem geral, e de ordem psychicas.

Primeiramente referindo-nos a seu syndrome excito-motor, vemos que elle está caracterisado, no tremor que se evidencia no braço esquerdio.

E' um tremor isolado, e como Achard definiu, o tremor do syndromo excito-motor tem oscillações rythamadas, rapidas e de fraca amplitude sob a influencia das contracções involuntarias dos mųsculos.

O syndromo parksoniano, é patente pelo facies que se apresenta com certa immobilidade, um tanto somnolento, com a bocca semi-aberta, escorrendo saliva, e a sua hemiplegia.

Quanto ás manifestações de ordem neurologioa mós temos os reflexos de ordem alterada.

As de ordem geral, dão-se pela forma com que se mostra o individuo em seu aspecto emmagrecido, sua dysphagia, sua sudorése abundante, parecendo o que bem pode ser que este doente evolua para uma forma cachetizante, já assignaladia por G. Levy.

As manifestações tardias de ordem psychica, estão demonstradas, pela deformação do caracter, pois vimlos, que elle sendo anteriormente no estado pre-morbido, de genio bom, tornou-se irritado e impulsivo.

Tem uma insomnia, que se mostra agitada, e phenomenos de excitação sexual.

Com estes symptomas, accentuados, o nosso doentinho, tem um verdadeiro syndromo sypomaniaco.

$O$ seu raciocinio encontra-se conservado. 
A sua attenção, demonstra, porém, como vimlos, uma especie de viscosidade, uma lentidão, phenomenol esse já assignalado por Naville.

E' a bradyphrenia.

Aqui, todiavia, a bradyphrenia não se mostra como escreveu aquelle autor, sendo uma inhibição, uma viscosidade psychica, generalisada.

Mas a inhibição de tenção no nosso caso é patente.

Do confronto dos dois casos que tivemos a honna de vos apresentar, não podemos, e nem é esse o nosso desejo, tira conclusões; que possam esclarecer o intrincado assumpto, hoje em fóco, das perturbações mentaes e psychicas da encephalite nias creanças.

O nosso fim, é aqui tão somente, assignalar, as perturbações mentaes que se demlonstram com mais frequencia, nas sequelas da encephalite letrargica.

São ellas:

$1 .^{\circ}$ - as perturbações do canacter, que num dos casos, manifestaramse por uma mudança, e n'outro, por uma exageração dias principaes tenr dencias.

$2 .^{\circ}$ - $\mathrm{O}$ insitincto sexual, em ambos cedo manifestado, e já 'pervertido.

$3^{\circ}$ - A conservação, no méio de todas essas perturbações mentaes, do lado intellectual do psychismo.

4.* - As perturbações do Irythmo do somno.

\section{Oswaldo C. Barrefo}

\section{ANUNCIEM na "REVISTA de MEDICINA"}

MEDIANTE PEDIDO ENVIAMOS TABELAS DE PREÇOS E PRESTAMOS PRONTAMENTE QUAESQUER OUTRAS INFORMAÇŌES 